Universidade Tecnológica Federal do Paraná - UTFPR

Campus Ponta Grossa - Paraná - Brasil

ISSN: 1981-3686/v. 08, n. 01: p. 1251-1261, 2014

D.O.I.: $10.3895 / \mathrm{S} 1981-36862014000100010$
Revista Brasileira de Tecnologia

Agroindustrial

\title{
DETERMINAÇÃO DE MICRORGANISMOS INDICADORES DE CONDIÇÕES HIGIÊNICAS SANITÁRIAS NAS MÃOS DE MANIPULADORES DE ALIMENTOS
}

\section{SCREENING OF HYGIENE-INDICATOR MICROORGANISMS IN HANDS OF FOOD MANIPULATORS.}

\author{
Adelino da Cunha Neto ${ }^{1}$; Odívia Oliveira Rosa ${ }^{1}$ \\ ${ }^{1}$ Departamento de Alimentos e Nutrição, Faculdade de Nutrição, Universidade Federal de Mato \\ Grosso. adeneto@yahoo.com.bre odivia@terra.com.br
}

\begin{abstract}
Resumo
Este estudo objetivou verificar se manipuladores de estabelecimentos que produzem e comercializam alimentos em Cuiabá, MT, higienizaram adequadamente as mãos antes da preparação de alimentos. Para tanto, com swabs coletouse da mão dominante de 36 manipuladores de cinco estabelecimentos $(A, B, C, D$ e E), amostras para contagem de microrganismos indicadores, e assim classificar o nível de contaminação das mãos destes em leve, moderada e pesada. Um total de 21 manipuladores (58,3\%) não higienizava adequadamente as mãos, pois se detectou a presença de Staphylococcus coagulase positiva com contagens superiores a $10^{2} U F C / m a ̃ o$, deste total 2/21 (9,5\%) estava com contagens $>10^{4}$ UFC/mão, e $11 / 21(52,4 \%)>10^{3}$ UFC/mão, enquanto $8 / 21(38,1 \%)$ estavam entre $10^{3}$ e $10^{2} U F C / m a ̃ o$. Estes resultados foram observados em 25, 60, 90 e $100 \%$ dos manipuladores dos estabelecimentos $A, E, D$ e B, respectivamente. Embora $50 \%$ de manipuladores do estabelecimento B apresentaram Coliformes a $45^{\circ} \mathrm{C}$ nas mãos, não foi detectada Salmonella spp. em nenhuma das mãos examinadas. Os manipuladores na sua maioria tiveram as mãos classificadas como contaminadas 21/36 (58,3\%) e somente 15/36 (41,7\%) como "mãos limpas". A contaminação das mãos foi classificada em: leve 8/36 (22,2\%), moderada 13/36 (33,3\%) e 1/36 (2,8\%) com contaminação pesada. As condições higiênico-sanitárias insatisfatórias das mãos representam riscos de desenvolvimento de toxi-infecção alimentar para os consumidores dos alimentos manipulados por estes colaboradores.

Palavras-chave: manipuladores de alimentos, lavagem das mãos, micro-organismos indicadores.
\end{abstract}

\section{Introdução}

A elaboração de alimentos com padrões higiênicos satisfatórios é uma das condições essenciais para promoção e prevenção da saúde, e o inadequado controle destas condições é um dos fatores responsáveis pela ocorrência dos surtos de doenças de origem alimentar (AJAO; ATERE, 2009).

Doenças conhecidas por contribuírem para a morbidade e mortalidade humana, bem como para o aumento do custo dos cuidados a saúde. No entanto, estas não afetam significativamente tão somente as pessoas saudáveis, mas também seu bem estar, tendo conseqüências financeiras individuais, familiares, comunitárias, na indústria de alimentos e na economia nacional. Sendo um 
dos maiores problemas de saúde internacional, e uma importante causa da redução do crescimento econômico de alguns países (SOUZA; SANTOS, 2009; ISARA et al. 2010).

Os alimentos estão expostos durante sua elaboração, a uma série de perigos ou oportunidades de contaminação microbiana, que podem estar relacionadas ás práticas inadequadas de processamento e de manipulação. Dados sobre fatores de risco para doenças de origem alimentar indicam que a maioria dos surtos resulta de falhas nas práticas de manipulação de alimentos (LITZ et al. 2007; LUES; Van TONDER, 2007).

Os manipuladores de alimentos apresentam um importante papel na segurança alimentar, e na ocorrência de intoxicações alimentares, porque eles podem introduzir patógenos nos alimentos durante o processo de produção, preparação e/ou distribuição. Podendo esses microrganismos ser transferidos de uma superfície, de outro alimento e/ou de mãos contaminadas para o alimento (SOUZA; SANTOS, 2009; GITHIRI; OKEMO; KIMIYWE, 2009).

Segundo Kochanski et al., (2009) mesmo os manipuladores sadios abrigam na pele, boca, nariz, garganta e trato intestinal, bactérias que podem contaminar os alimentos. A pele das mãos apresenta bactérias que podem ser classificadas em dois grupos as residentes e as transitórias.

A microbiota residente é composta na sua maioria por bactérias gram-positivas, localizadas nas camadas mais profundas da pele, encontram-se em equilíbrio dinâmico como parasita ou saprófito da pele, é mais difícil de ser removida, e normalmente não está associada à contaminação cruzada (CUSTÓDIO et al. 2009).

Já os microrganismos presentes na flora transitória, são representados principalmente pelas bactérias gram-negativas, que colonizam a camada superior da pele são facilmente removidos pela conscienciosa lavagem das mãos com bons detergentes, e são freqüentemente adquiridos pelo contato com superfícies contaminadas (CUSTÓDIO et al. 2009).

Por isto, Shojaei et al., (2006) ressaltam que é geralmente aceito que as mãos de manipuladores sejam um importante veiculo de contaminação cruzada de alimentos, e que a melhora na higiene pessoal e escrupulosa lavagem das mãos podem levar ao controle básico da difusão de microrganismos transitórios potencialmente patogênicos.

A lavagem das mãos é uma medida eficaz de prevenção da transmissão cruzada de microrganismos e, apesar da relativa simplicidade deste procedimento, ainda se observa uma forte resistência em sua utilização. A higienização adequada dos equipamentos e utensílios bem como a do próprio manipulador é um dos fatores mais importante nos processos para o controle de qualidade do alimento (KOCHANSKI et al. 2009; CUSTÓDIO et al. 2009).

Nas Unidades de Alimentação e Nutrição (UAN), é reconhecida a transferência de microrganismos aos comensais, via alimentação, proveniente de diversas fontes, além do próprio alimento. Os alimentos ficam mais expostos a uma série de perigos ou oportunidades de 
contaminações microbianas associadas a práticas incorretas de manipulação e processamentos (AYÇIÇEK et al. 2004; MESQUITA et al. 2006).

Isara et al., (2010) esclarecem que mais de 1/3 da população dos países desenvolvidos é afetada pela doença de origem alimentar a cada ano, e que nos países em desenvolvimento este problema é muito mais amplo, pois, já que sua população é mais susceptíveis às doenças e mortes devido ao estado de pobreza e inadequação das práticas higiênicas. Doenças diarréicas originárias da água ou alimentos são vistas como a causa de agravos a saúde e mortes nesses países, matando uma população estimada de 2,2 milhões de pessoas, e muitas das quais são crianças.

Sousa (2008) observa que o padrão de higiene pode ser medido pela análise de microrganismos indicadores, e compreendem grupos de microrganismos que são exclusivamente ou em conjunto utilizados para verificar a característica e as condições higiênicas dos alimentos.

Objetivando verificar o padrão de higiene dos manipuladores de alimentos, diferentes pesquisadores implementam estudos para detecção de patógenos e microrganismos indicadores tais como: bactérias do grupo Coliformes totais e termotolerantes ou $45^{\circ} \mathrm{C}$, Escherichia coli, Enterobacteriaceae; Bacillus cereus, Clostridium perfringens, Salmonella spp., bactérias mesófilas aeróbias, bactérias gram positivas e negativas da flora e contaminantes (LITZ et al. 2007; LUES; Van TONDER, 2007; CUSTÓDIO et al. 2009; SHOJAEI; SHOOSHTARIPOOR; AMIRI, 2006; AYÇIÇEK et al. 2004; MESQUITA et al. 2006; OLIVEIRA et al. 2006; COSTA; GABAN; LEAL, 2002). Dentre os microrganismos investigados os cocos gram-positivos do gênero Staphylococcus é o mais detectado nas mãos dos manipuladores. Estudos avaliando o número populacional destes, e o seu comportamento quanto à resistência a antimicrobiano, e sua potencial capacidade de produzir enterotoxinas são desenvolvidos (KOCHANSKI et al. 2009; WEI; CHIOU, 2002; RAPINI et al. 2005; GRANDO et al. 2008; UDO; AL-MUFTI; ALBERT, 2009; MARTINS et al. 2009; RALL et al. 2010; MARINO et al. 2010).

Este trabalho teve o objetivo de averiguar o possível papel dos manipuladores quanto veículo de microrganismos patogênicos ao alimento. Neste propósito se verificou a contagem de microrganismos indicadores nas mãos de manipuladores de alimentos, e se as contagens estavam dentro dos critérios de população de microrganismos descritos por Silva Jr., (2005); e classificá-las quando contaminadas, com contaminação leve, moderada ou pesada, segundo Shojaei et al., (2006). Avaliando manipuladores atuantes numa indústria de sorvete, num lactário hospitalar, numa cooperativa de produção de banana e mandioca chips, numa Unidade de Alimentação e Nutrição (UAN) hospitalar e num restaurante universitário, da cidade de Cuiabá, MT, deste modo, considerando que os manipuladores higienizavam as mãos adequadamente ou não. 


\section{Material e Métodos}

Trata-se de um estudo quali-quantitativo retrospectivo de resultados analíticos contidos em cinco relatórios de inspeções realizadas de 31/08/2010 a 05/10/2010, pertencentes ao arquivo de dados das análises realizadas pela equipe do Laboratório de Análise microbiológica de Alimentos, Departamento de Alimentos e Nutrição, Faculdade de Nutrição, Universidade Federal de Mato Grosso. Estas inspeções foram efetuadas em estabelecimentos que trabalham com a produção e distribuição de alimentos prontos para o consumo, tais como, indústria de sorvete, lactário hospitalar, cooperativa de produção de banana e mandioca chips, Unidade de Alimentação e Nutrição (UAN) hospitalar e restaurante universitário. A inspeção compreendeu a visita, nos estabelecimentos e a coleta de amostras das mãos pela técnica de swab, (SVEUM et al. 1992) para a determinação da ocorrência e da população de Coliformes a $45^{\circ} \mathrm{C}$, Staphylococcus coagulase positiva e Salmonella spp.

A coleta foi realizada em 36 manipuladores, na mão dominante de cada manipulador, utilizando-se swabs estéreis os quais foram umedecidos com solução fisiológica a $0,85 \%$, passados na palma e dorso da mão, entre dedos e sob as unhas dos manipuladores durante o processo de produção e distribuição dos alimentos. O swab foi introduzido em um tubo contendo $10 \mathrm{ml}$ de solução fisiológica $(0,85 \%)$, o tubo foi fechado, identificado e acondicionado em caixa isotérmica, e encaminhado para o laboratório de microbiologia para análise (SVEUM et al. 1992).

Os swabs com a solução fisiológica foram homogeneizados em agitador de tubos, tipo vortex, por um minuto, este homogeneizado constituiu a diluição $10^{-1}$ e se realizou diluições subseqüentes até $10^{-3}$, das quais se inoculou uma alíquota de $0,1 \mathrm{ml}$ das diluições na superfície do Agar Eosina e Azul de Metileno, segundo Levine (EMB-Levine), Agar Baird-Parker (BPA) e dos Agar Verde Brilhante (BGA) e Agar Rambach (RA), objetivando a contagem e isolamento de Coliformes a $45^{\circ} \mathrm{C}$, Staphylococcus coagulase positiva e Salmonella spp., esta alíquota foi distribuída com o uma alça de Drigalski descartável. Posteriormente as placas foram incubadas a $35^{\circ} \mathrm{C}$ por $24 / 48$ horas, e verificou-se a ocorrência de colônias típicas, que foram contadas e isoladas para identificação, através de testes bioquímicos, tais como: Indol, Vermelho de Metila, VogesProuskauer e Citrato de Simmons (IMVIC/E. coli); coloração de gram e aos testes de catalase e coagulase (Staphylococcus spp.) e provas bioquímicas em Kit de identificação rápida para enterobactérias [Salmonella spp.] (SVEUM et al. 1992).

Verificou-se, através da análise de Coliformes a $45^{\circ} \mathrm{C}$, Salmonella spp., e Staphylococcus coagulase positiva, se os manipuladores dos estabelecimentos apresentavam-se com a higiene das mãos satisfatórias segundo os critérios de populações de microrganismos descritos por Silva Jr.(2005), que preconiza ausência de Coliformes a $45^{\circ} \mathrm{C}$, e também de B. cereus, Pseudomonas 
aeruginosa, e para contagem de Staphylococcus coagulase positiva é aceita uma população de até 100 (10² UFC/Unidade Formadora de Colônias) para swab de mãos. Neste estudo o critério para Salmonella spp. foi o mesmo dos Coliformes a $45^{\circ} \mathrm{C}$ (fecais), ou seja ausência. Também se classificou o nível de contaminação das mãos, pelo número da população de microrganismos (UFC/mão): em leve contaminação $\leq$ que $10^{3} \mathrm{UFC} /$ mão, moderada de $10^{3}$ a $10^{6} \mathrm{UFC} /$ mão e pesada $\geq$ que $10^{6} \mathrm{UFC} / \mathrm{mão}$ (SHOJAEI; SHOOSHTARIPOOR; AMIRI, 2006).

\section{Resultados}

Dos 36 manipuladores de cinco estabelecimentos analisados somente os do estabelecimento denominado "C" apresentaram resultados satisfatório, quanto à higienização das mãos em todos os seus manipuladores, segundo os critérios preconizados por Silva Jr., (2005). Já os manipuladores dos estabelecimentos A, B, D e E, apresentaram contagens de Staphylococcus coagulase positiva acima de $10^{2}$ UFC/mão (SILVA Jr. 2005) em 25\% (A), $60 \%$ (E), 90\% (D) e 100\% (B) após a análise, (Tabela 1).

Outro grupo de microrganismos presentes foram os Coliformes a $45^{\circ} \mathrm{C}$ em $50 \%$ dos manipuladores do estabelecimento B, com contagens de $3,5 \times 10^{3} \mathrm{UFC} /$ mão e de 5,0 x $10^{6} \mathrm{UFC} /$ mão, respectivamente, (Tabela 1). No entanto, ao verificar o número de manipuladores contaminados com Coliformes a $45^{\circ} \mathrm{C}$, em relação ao total de indivíduos avaliados, notou-se que foram positivos somente $2 / 36$, representando $5,55 \%$ da população.

Quanto às contagens de Staphylococcus coagulase positiva verificou-se que a população variou de $1,0 \times 10^{2} \mathrm{UFC} /$ mão até $1,41 \times 10^{4} \mathrm{UFC} / \mathrm{mão}$, sendo que os dois extremos de contagem foram detectados no estabelecimento E. Observou-se que 21/36 (58,3\%) dos manipuladores apresentaram positivos para ocorrência de Staphylococcus coagulase positiva, deste total 9,5\% $(2 / 21)$ estavam com contagens > $10^{4} \mathrm{UFC} /$ mão, e $52,4 \%(11 / 21)>10^{3} \mathrm{UFC} /$ mão e $38,1 \%(8 / 21)$ entre $10^{3}$ e $10^{2} \mathrm{UFC} /$ mão.

As mãos de $100 \%$ dos manipuladores do estabelecimento C, $75 \%$ do A e $40 \%$ do E, enquadram-se na classificação de mãos limpas. Já as mãos de $50 \%$ dos manipuladores do estabelecimento D e $20 \%$ do estabelecimento E, com contagens de microrganismos < que $10^{3} \mathrm{UFC} / m a ̃ o$ classificam-se no nível leve de contaminação. Mão com nível de contaminação moderada encontrava-se em $25 \%$ dos manipuladores do estabelecimento A, $75 \%$ do B, 50\% do D e $30 \%$ do E. Somente $25 \%$ dos manipuladores do estabelecimento B, apresentavam mãos com contaminação pesada (Tabela 2) (SHOJAEI; SHOOSHTARIPOOR; AMIRI, 2006). 
Tabela 1 - Distribuição das contagens de microrganismos em UFC/mão por estabelecimento e mão do manipulador

\begin{tabular}{cccc}
\hline \multicolumn{2}{c}{ População em UFC de microrganismos contidos nas mãos } & Estabelecimentos/ \\
manipuladores
\end{tabular}
Restaurante Industrial; E= Unidade de Alimentação e Nutrição hospitalar.

Somente $36,1 \%$ dos manipuladores apresentaram contagens de microrganismos que os classificaram quanto ao nível de contaminação, em moderada e pesada, sendo 13/36 e 1/36, respectivamente. Permanecendo assim a maioria dos manipuladores com as mãos limpas (15/36), e/ou com uma contaminação menor que $10^{3} \mathrm{UFC} /$ mão, que caracteriza contaminação leve, apresentada por 8/36 dos indivíduos avaliados (SHOJAEI; SHOOSHTARIPOOR; AMIRI, 2006).

Tabela 2 - Classificação dos níveis de higiene das mãos dos manipuladores em UFC/mão, por estabelecimento, frequiência e seus percentuais.

\begin{tabular}{ccccccc}
\hline Higiene das mãos & \multicolumn{5}{c}{ Freqüiência/percentual de manipulador por } \\
\hline Classificação & \multicolumn{5}{c}{ Estabelecimentos } & Total \\
\cline { 2 - 6 } & A & B & C & D & E \\
Mãos limpas & $3 / 75 \%$ & - & $8 / 100 \%$ & - & $4 / 40 \%$ & $15 / 41,7 \%$ \\
Contaminação UFC/mão & & & & & & \\
Leve $\leq$ que $10^{3}$ & - & - & - & $4 / 40 \%$ & $3 / 30 \%$ & $7 / 22,2 \%$ \\
Moderada de $10^{3}$ a $10^{6}$ & $1 / 25 \%$ & $3 / 30 \%$ & - & $6 / 60 \%$ & $3 / 30 \%$ & $13 / 33,3 \%$ \\
Pesada $\geq$ que $10^{6}$ & - & $1 / 25 \%$ & - & - & - & $1 / 2,8 \%$ \\
\hline
\end{tabular}

Legenda: $\mathrm{A}=$ Restaurante comercial; $\mathrm{B}=$ Cooperativa de produtores de alimentos: $\mathrm{C}=$ Lactário hospitalar; $\mathrm{D}=$ Restaurante Industrial; E= Unidade de Alimentação e Nutrição hospitalar.

\section{Discussão}

Segundo Ajao \& Atere, (2009) a verificação da presença de organismos indicadores, patógenos ou elevada contagem geral de bactérias em gêneros alimentícios, superfícies de contato 
com o alimento, equipamentos e utensílios, prove uma direta e relevante medida da eficiência da limpeza e higiene no ambiente do alimento.

Dentre os microrganismos averiguados, Staphylococcus coagulase positiva e Coliformes a $45^{\circ} \mathrm{C}$ (Fecais), e Salmonella spp., nas mãos dos manipuladores. O gênero Staphylococcus foi o de maior ocorrência, no entanto, seu percentual foi menor que o encontrado por Lues \& Van Tonder, (2007) de 88\% nas mãos manipuladores da África do Sul; e por Ayçiçek et al., (2004) de 70\% em manipuladores de um hospital de Etlik-Ankara, Turquia; e também por Kochanski et al., (2009) de $100 \%$ em manipuladores de alimentos no centro-oeste do Brasil; e em Campo Grande, MS, 89,6\%, por Costa et al., (2002). Todavia, apresenta percentuais de ocorrência similar aos de Marino et al. (2010) pesquisando o gênero Staphylococcus sp. em Udine, Itália, verificaram que de 23 mãos de manipuladores com luvas, 46,3\% estavam positivas totalizando 108 cepas das quais 50 eram de $S$. aureus, 25 de S. epidermidis, 27 de S. saprophyticus e 6 S. pausteri. Porém, os percentuais de contaminação aqui encontrados são superiores aos de 12,6\% dos manipuladores avaliados por Shojaei et al., (2006); bem como dos 24\% de 100 manipuladores examinados por Martins et al., (2009) em Fortaleza, CE; também dos 16,5\% detectados em manipuladores de alimentos na cidade de Gondar, Etiópia por Andargie et al., (2008).

Segundo Silva Jr., (2005) a Organização Mundial da Saúde (WHO) e Associação Americana de Saúde Pública (APHA), preconizam a ausência de bactéria do grupo Coliforme fecal, também denominada de Coliforme termotolerantes ou Coliforme a $45^{\circ} \mathrm{C}$. Entretanto, neste estudo detectou-se esse grupo de microrganismo em 5,55\% dos manipuladores de alimentos, valores similares aos encontrados por Ayçiçek et al., (2004) num hospital de Etlik-Ankara, Turquia com 7,8\% de E. coli nas mãos dos manipuladores de alimentos; e de Andargie et al., (2008) na cidade de Gondar, Etiópia, em que 3,1\% das mãos estavam contaminados com E. coli. Todavia, esses percentuais de E. coli são inferiores aos $22 \%$ verificados por Shojaei et al., (2006); ou por Campos et al., (2009) em Natal, Brasil, que detectaram que 55,6\% das mãos dos manipuladores avaliados estavam contaminadas com Coliformes a $45^{\circ} \mathrm{C}$.

A presença de microrganismos, tais como, Staphylococcus coagulase positiva e Coliforme a $45^{\circ} \mathrm{C}$ em elevado número populacional, mostrou que as mãos dos manipuladores encontravam-se contaminadas, por tanto, indicando que o processo de higienização destas não está sendo eficaz. O Staphylococcus spp., a Escherichia coli e a Salmonella spp. são os principais microrganismos relacionados com a prática de manipulação de alimentos. Pois, a presença de Escherichia coli e de outras bactérias do grupo das enterobactérias geralmente indicam a contaminação fecal de água e alimentos. E a detecção de S. aureus microrganismo que tem como um dos seus maiores reservatórios o ser humano, configura contaminação pós-processo dos alimentos (SOUSA, 2008). 
Shojaei et al., (2006) analisando microrganismos em manipuladores de alimentos encontraram S. aureus e E. coli, em 72, 7\% destes (109/150). Observando o nível de contaminação, estes verificaram que $80,7 \%$ de 109 se apresentavam com contaminação pesada, $12,8 \%$ moderada e 6,5\% leve. Resultados similares quanto à ocorrência dos grupos de microrganismos Staphylococcus coagulase positiva e Coliformes a $45^{\circ} \mathrm{C}$, contudo, os percentuais pertinentes ao nível de contaminação leve de 22,2\%, dos manipuladores, 33,3\% moderada e 2,8\% pesada, classificação inversa à encontrada por Shojaei et al., (2006) com predomínio de manipuladores com mãos classificadas como limpas $41,7 \%$.

Staphylococcus coagulase positiva apresentou elevado percentual de detecção, o que poderia ocorrer, pois, este grupo de microrganismo representado pela espécie $S$. aureus é encontrado na pele e mucosa do ser humano, em uma população de $10^{3}$ a $10^{6} \mathrm{UFC} / \mathrm{cm}^{2}$ nas áreas úmidas e 10 a $10^{3} \mathrm{UFC} / \mathrm{cm}^{2}$ nas áreas secas (JAY, 2005). Segundo Cardoso et al., (1999) os sabões utilizados para lavagem das mãos tem a capacidade de reduzir aproximadamente uma população de $10^{3} \mathrm{UFC} / \mathrm{cm}^{2}$ bactérias gram negativas, sendo efetiva para remover bactérias de mãos com contaminação leve. Portanto, é ineficiente quando a mão apresentar um nível de contaminação pesada ( $\geq$ que $10^{6} \mathrm{UFC} / \mathrm{cm}^{2}$ ). Litz et al., (2007) afirmam que entre aos agentes químicos utilizados na higienização das mãos o álcool etílico a $70 \%$ e povidine-iodine a $10 \%$ são os agentes mais efetivos, no controle de microrganismos.

Segundo Jay (2005) a detecção de enterotoxinas estafilocócicas em alimentos normalmente é efetivada, naqueles produtos que apresentam uma população $S$. aureus de $10^{4}$ a $10^{8} \mathrm{UFC} / \mathrm{g}$ ou ml do produto avaliado. Este também afirma que o $S$. aureus é incapaz de competir com a flora acompanhante, tanto em alimentos frescos como em congelados, que a biota saprófita, por uma ação antagônica inibe o seu crescimento mesmo e um ambiente favorável. O que leva a concluir que quanto maior a população deste microrganismo é carreada ao alimento, maior será a possibilidade de crescimento e consequente produção de biotoxina.

Cientes de que a ação do sabão diminui em até $10^{3} \mathrm{UFC} / \mathrm{cm}^{2}$ da população de microrganismos das mãos, e que os anti-sépticos diminuem expressivamente a sua população reduzindo a níveis seguros (LITZ et al. 2007; CARDOSO et al. 1999). Sugere-se que se utilize a classificação das mãos dos manipuladores de alimentos proposta por Shojaei et al., (2006), em mão limpa, com ausência de microrganismos, e a presença destes, classificando-as em mão com contaminação leve, moderada e pesada, como mecanismos de avaliação pós processo de higienização das mãos pelos colaboradores. Mostrando assim, para supervisores e gerentes de serviços de produção de alimentos, se o procedimento de lavagem das mãos está sendo realizado de forma adequada e com substancias eficientes, que removam ou diminuam a população de microrganismos patogênicos das mãos dos manipuladores de alimentos. 
Os manipuladores de alimentos apresentam um importante papel na segurança alimentar, e na ocorrência de toxi-infecção alimentar (GITHIRI; OKEMO; KIMIYWE, 2009). Segundo Andargie et al., (2008) um meio para prevenir a transmissão de patógenos para os alimentos via manipuladores é a adesão irrestrita às boas práticas de higiene pessoais, e as práticas de manipulação higiênica dos alimentos.

Embora os manipuladores possam entender da necessidade da higiene pessoal, eles não compreendem o aspecto crucial da limpeza das superfícies que entram em contato como o alimento. Levando assim a falta de aplicação do conhecimento adquirido de higiene dos alimentos, e a conseqüente contaminação destes, e o desenvolvimento de quadros de toxi-infecções alimentares (WALKER; PRITCHARD; FORSYTHE, 2003; WEI; CHIOU, 2002). O melhor meio para reduzir esses riscos é o treinamento das pessoas envolvidas na manipulação de alimentos (SOUSA, 2008).

A não aplicação pelos manipuladores dos conhecimentos adquiridos sobre a manipulação higiênica dos alimentos é por razões inerentes a esta categoria, tais como: recrutamento de pessoal de classe sócio-econômica baixa, com baixo nível de escolaridade e troca rápida de funcionário (WALKER; PRITCHARD; FORSYTHE, 2003; WEI; CHIOU, 2002). E também pelo aumento sazonal de funcionários, problemas de alfabetização e linguagem, pouca motivação devido à baixa remuneração e o baixo status do trabalho. Razões as quais mostram que só o conhecimento não reverte à estagnação dos manipuladores, levando-os então a troca nas práticas de manipulação dos alimentos (WEI; CHIOU, 2002).

\section{Conclusão}

Os manipuladores dos estabelecimentos que comercializam alimentos em Cuiabá, MT, avaliados, não higienizavam adequadamente as mãos, pois, detectou-se a presença de coliformes a $45^{\circ} \mathrm{C}$, e Staphylococcus coagulase positiva com população acima de $10^{2} \mathrm{UFC} / \mathrm{mão}$, na maioria das mãos de manipuladores, estando assim em desacordo com os critérios estabelecidos e descritos. Dentre as mãos contaminadas aquelas classificadas com contaminação moderada e pesada, representaram o maior número mãos, mostrando que potencialmente pode haver risco de que os consumidores dos alimentos produzidos por estes manipuladores possam desenvolver um toxiinfecção alimentar.

\footnotetext{
Abstract

This study aimed to check the hands hygienic status of food manipulators from Cuiabá, MT, before food processing. To achieve this, swab samples were collected from the preferred hand of 36 food handlers from five institutions $(A, B, C, D$ and $E$ ) and screened for indicator-microorganisms counting to classify the level of hand contamination as low, moderate or high. A total of 21 manipulators (58.3\%) appeared not to hygienize adequately their hands, due to the carriage of coagulase positive Staphylococcus counts higher than 10²CFU/hand. Among them, 2/21 (9.5\%) showed
} 
counts $>10^{4}$ CFU/hand and 11/21 (52.4\%) > $10^{3}$ CFU/hand, whereas in $8 / 21$ (38.1\%) counts ranged from $10^{3}$ to $10^{2}$ CFU/hand. These results were observed in $25,60,90$ and $100 \%$ of handlers from institutions $A, E, D$ and $B$ respectively. Furthermore, 50\% of manipulators from institution B were positive for $45{ }^{\circ} \mathrm{C}$ coliforms and Salmonella were not detected in none of the examined subjects. The handlers were mostly classified as contaminated hands 21/36 (58.3\%) and only 15/36 (41.7\%) as "clean hands". The contamination of hands was classified as: mild 8/36 (22.2\%), moderate $13 / 36(33.3 \%)$ and $1 / 36(2.8 \%)$ with heavy contamination. The hand sanitary-hygienic status of the food manipulators examined in this study represents a risk of foodborne to their consumers.

Key-words: Food handlers, hand washing, indicator-microorganisms.

\section{Referências}

AJAO, A. T. ATERE, T. G. Bacteriological assessment and hygienic standard of food canteens in Kwara state Polytechnic, Ilorin, Nigeria. African Scientist, v.10, n. 3, p.173-180, 2009.

ANDARGIE, G.; KASSU, A.; MOGES, F.; TIRUNEH, M.; HURUY, K. Prevalence of bacteria and intestinal parasites among food-handlers in Gondar Town, Northwest Ethiopia. Journal of Health, Population and Nutrition. v. 26, n. 4, p. 451-455, dec., 2008.

AYÇIÇEK, H.; AYDOĞAN, H.; KÜÇÜKKARAASLAN, A.; BAYSALLAR, M.; BAŞUSTAOĞLU, A. C. Assessment of the bacterial contamination on hands of hospital food handlers. Food Control, v. 15, p.253-259, 2004. http://dx.doi.org/10.1016/S0956-7135(03)00064-1

CAMPOS, A. K. C.; CARDONHA, A. M. S.; PINHEIRO, L. B. FERREIRA, N. R.; AZEVEDO, P. R. M.; STAMFORD, T. L.M. Assessment of personal hygiene and practices of food handlers in municipal public schools of Natal, Brazil. Food Control, v. 20, p. 807-810, 2009. http://dx.doi.org/10.1016/j.foodcont.2008.10.010

CARDOSO, C. L.; PEREIRA, H. H.; ZEQUIM, J. C.; GUILLERMETTI, M. Effectiveness of hand-cleansing agents for removing Acinetobacter baumannii strain form contaminated hands. American Journal Infection Control, v. 27, n. 4, p.327-331, 1999. http://dx.doi.org/10.1016/S0196-6553(99)70052-0

COElHO, A. I. M.; MilagReS, R. C. M.; MARTINS, J. F. L.; AZEREDO, R. M. C.; SANTANA, A. M. C. Contaminação microbiológica de ambientes e de superfícies em restaurantes comerciais. Ciências \& Saúde Coletiva, v. 15, supl. 1, p. 1597-1606, 2010.

COSTA, S. R.; GABAN, C. R. G.; LEAL, C. R. B. Deteç̧ão de Staphylococcus aureus nas mãos e narinas de manipuladores de alimentos e avaliação das condições higiênicas das cozinhas, em escolas estaduais no município de Campo Grande, MS. Ensaios e Ciência, v. 6, n. 02, p. 49-56, 2002.

CUSTÓDIO, J.; ALVES, J. F.; SILVA, F. M; DOLINGER, E. J. O. V.; SANTOS, J. G. S.; BRITO, D. V. D. Avaliação microbiológica das mãos de profissionais da saúde de um hospital particular de Itumbiara, Goiás. Revista Ciências Médicas. Campinas, v. 18, nº. 1, jan-fev. p. 7-11, 2009.

GITHIRI, M.; OKEMO, P.; KIMIYWE, J. Hygienic practices and occurrence of coliforms and Staphylococcus on food at a public hospital in Kenya. Journal of Applied Biosciences,v.27, p. 1727-1731, 2009.

GRANDO, W. F.; SCAPIN, D.; MALHEIROS, P. S.; ROSSI, E. M.; TONDO, E. C. Suscetibilidade a antimicrobianos de Staphylococcus aureus isolados de manipuladores de indústria de laticínios. Alimentos e Nutrição. Araraquara, v. 19, n. 4, out./dez. p.467-471, 2008.

ISARA, A. R.; ISAH, E. C.; LOFOR, P. V. O.; OJIDE, C. K. Food contamination in fast food restaurants in Benin city, Edo state, Nigeria: implications for food hygiene and safety. Public Health, v. 124, p. 467-471, 2010. http://dx.doi.org/10.1016/j.puhe.2010.03.028

JAY, J. M. Microbiologia de Alimentos. 6a edição, Porto Alegre, Artmed, 2005.

KOCHANSKI, S.; PIEROZAN, M. K.; MOSSI, A. J.; TREICHEL, H.; CANSIAN, R. L.; GHISLENI, C. P.; TONIAZZO, G. Avaliação das condições microbiológicas de uma Unidade de Alimentação e Nutrição. Alimentos e Nutrição, v.20, n. 4, p.663-668, 2009.

LITZ, V. M.; RODRIGUES, L. B.; SANTOS, L. R.; PILOTTO, F. Anti-sepsia de mãos na indústria de carnes: avaliação da clorhexidina. Triclosan e iodóforo na redução da contaminação microbiana em manipuladores. Acta Scientiae Veterinariae, v.35, n.3, p.321-326, 2007. 
LUES, J. F. R.; Van TONDER, I. The occurrence of indicator bacteria on hands and aprons of food handlers in the delicatessen sections of a retail group. Food Control, v. 18, p. 326-332, 2007. http://dx.doi.org/10.1016/j.foodcont.2005.10.010

MARINO, M.; FRIGO, F.; BARTOMEIOLI, I.; MAIFRENI, M. Safety-related properties of Staphylococci isolated from food and food environments. Journal Applied Microbiology, v. 110, p.550-561, 2010. http://dx.doi.org/10.1111/j.1365-2672.2010.04909.x

MARTINS, S. C. S.; MARTINS, C.M.; ALBUQUERQUE, L. M. B.; FONTELES, T.V.; REGO, S. L.; FAHEINA JUNIOR, G. S. Perfil de resistência de cepas de Staphylococcus coagulase positiva isoladas de manipuladores de alimentos. Boletim do Centro de Processamento de Alimentos. v.27, n. 1, p.43-52, 2009.

MESQuitA, M. A.; DANIEL, A. P.; SACCOL, A. L. F.; MILANI, L. I. G.; FRIES, L. L. M. Qualidade microbiológica no processamento do frango assado em Unidade de Alimentação e Nutrição. Ciência e Tecnologia de Alimentos, v. 26, n. 1, p.198-203, 2006. http://dx.doi.org/10.1590/S0101-20612006000100031

OLIVEIRA, A. C. G.; SEIXAS, A. S. S.; SOUSA, C. P.; SOUZA, C. W. O. Microbiological evaluation of sugarcane juice sold at street stands and juice handling conditions in São Carlos, São Paulo, Brazil. Cadernos de saúde Pública, v.22, n. 5, p.1111-1114, 2006. http://dx.doi.org/10.1590/S0102-311X2006000500024

RALL, V. L. M.; SFORCIN, J. M.; AUGUSTINI, V. C.; WATANABE, M. T.; FERNANDES Jr., A.; RALL, R.; SILVA, M. G.; ARAÚJO Jr., J. P. Detection of enterotoxin genes of Staphylococcus sp. Isolated from nasal cavities and hands of food handlers. Brazilian Journal of Microbiology, v. $41, \quad$ n.1, p. $59-65, \quad 2010$. http://dx.doi.org/10.1590/S1517-83822010000100011

RAPINI, L. S.; CERQUEIRA, M. M. O. P.; CARMO, L. S.; VERAS, J. F.; SOUZA, M. R. Presença de Staphylococcus spp. produtores de enterotoxinas e da toxina da síndrome do choque tóxico em manipuladores de queijo de cabra. Arquivo Brasileiro de Medicina Veterinária e Zootecnia, v. 57, n. 6, p.825-829, 2005. http://dx.doi.org/10.1590/S0102-09352005000600019

SHOJAEI, H.; SHOOSHTARIPOOR, J.; AMIRI, M. Efficacy of simple hand-washing in reduction of microbial hand contamination of Iranian food handlers. Food Research International,v. 39, p. 525-529, 2006. http://dx.doi.org/10.1016/j.foodres.2005.10.007

SILVA Jr. E. A. Manual de Controle Higiênico-Sanitário em Serviços de Alimentação. Editora Varela. 6 ed., 2005. $623 \mathrm{p}$.

SOUSA, C. P. The impact of food manufacturing practices on food borne diseases, Brazil. Brazilian Archives of Biology And Technology an International Journal, v. 51, n. 4, p.815-823, 2008. http://dx.doi.org/10.1111/j.17454565.2009.00166.x

SOUZA, P. A.; SANTOS, D. A. Microbiological risk factor associated with food handlers in elementary schools from Brazil. Journal of Food Safety, v. 29, p. 424-429, 2009.

SVEUM, W. H.; MOBERG, L. J.; RUDE, R. A.; FRANK, J. F. Microbiological monitoring of the food processing environment. In: VANDERZANT, C.; SPLITTSTOESSER, D. F.; SPECK, M. L. (Eds.). Compendium of methods for the microbiological examination of foods. 3. ed. Washington: APHA, 1992. cap. 3, p. 51-7

UDO, E. E.; AL-MUFTI, S.; ALBERT, J. The prevalence of antimicrobial resistance and carriage of virulence genes in Staphylococcus aureus isolated from food handlers in Kuwait city restaurants. BMC Research Notes, v. 2, n. 108,2009

WALKER, E.; PRITCHARD, C.; FORSYTHE, S. Food handlers' hygiene knowledge in small food businesses. Food Control. v. 14, p. 339-343, 2003. http://dx.doi.org/10.1016/S0956-7135(02)00101-9

WEI, H. L.; CHIOU, C. S. Molecular subtyping of Staphylococcus aureus from an outbreak associated with a food handlers. Epidemiology and Infection, v. 128, p. 15-20, 2002. http://dx.doi.org/10.1017/S0950268801006355

*Dados parciais foram apresentados no "XVII Congresso Nacional de Analistas de Alimentos; III Encontro Latino Americano de Analistas de Alimentos" 03 a 07 de julho de 2011, Cuiabá, MT.

Submetido em 16 abr. 2013, Aceito para publicação em 20 dez. 2013. 